\title{
Chemical composition and antiparasitic activity of essential oils from leaves of Guatteria friesiana and Guatteria pogonopus (Annonaceae)
}

\author{
Cássio S. Meiraa, Leociley R. A. Menezes ${ }^{\mathrm{b}, \mathrm{c}}$, Tatiana B. dos Santos ${ }^{\mathrm{a}, \mathrm{d}}$, Taís S. Macedo ${ }^{\mathrm{a}}$, José E. N. Fontes ${ }^{\mathrm{b}, \mathrm{e}}$, Emmanoel \\ V. Costa ${ }^{f}$, Maria L. B. Pinheiro ${ }^{f}$, Thanany B. da Silva ${ }^{b}$, Elisalva Teixeira Guimarães ${ }^{a, d}$ and Milena B. P. Soares ${ }^{a, g}$ \\ ${ }^{a}$ Centro de Pesquisas Gonçalo Moniz, Fundação Oswaldo Cruz (FIOCRUZ), Salvador, BA, Brazil; bepartamento de Química, Universidade Federal \\ de Sergipe, São Cristóvão, SE, Brazil; 'CCentro de NMR, Universidade Federal do Paraná, Curitiba, PR, Brazil; 'Departamento de Ciências da Vida, \\ Universidade do Estado da Bahia, Salvador, BA, Brazil; 'Instituto de Química, UNICAMP, Campinas, SP, Brazil; fDepartamento de Química, Instituto \\ de Ciências Exatas, Universidade Federal de Amazonas, Manaus, AM, Brazil; ${ }^{9}$ Centro de Biotecnologia e Terapia Celular, Hospital São Rafael, \\ Salvador, BA, Brazil
}

\begin{abstract}
Natural products represent a valuable source for discovery of antiparasitic agents. Here, we describe the antiparasitic activity from essential oils extracted from leaves of Guatteria friesiana (EOGF) and Guatteria pogonopus (EOGP) (Annonaceae). The essential oils were obtained by hydrodistillation and analyzed by GC/MS and GC-FID. The sesquiterpenes are more abundant in both essential oils. G. friesiana are dominated by $\beta$-eudesmol (51.9\%), $\gamma$-eudesmol (18.9\%) anda-eudesmol (12.6\%). The major compounds identified for EOGP were spathulenol (24.8\%), $\gamma$-amorphene (14.7\%) and germacrene D (11.8\%). The essential oils demonstrated potent trypanocidal and antimalarial activities with values of $\mathrm{IC}_{50}$ lower than $41.3 \mu \mathrm{g} / \mathrm{mL}$. EOGF also inhibits the proliferation of amastigotes. In addition, we identified significant ultrastructural alterations induced by the essential oils, especially in the cell membrane, Golgi complex, endoplasmatic reticulum and mitochondria. The results presented herein reinforce the potential of other members of this family for search of antiparasitic compounds.
\end{abstract}

\section{ARTICLE HISTORY}

Received 1 December 2015

Accepted 3 July 2016

\section{KEYWORDS}

Guatteria friesiana; Guatteria pogonopus; essential oil; antimalarial activity; trypanocidal activity

\section{Introduction}

Chagas disease and malaria are caused by protozoan parasites and constitute serious public health problems worldwide, mainly in tropical countries (1). Pharmacotherapy of both diseases is limited to a small number of drugs, which are associated with several side effects, variable efficacy and resistance $(2,3)$. These challenges, combined with the lack of a vaccine for both diseases make the research and development of new antiparasitic agents a matter of great relevance to public health.

The genus Guatteria (Annonaceae) comprises 307 species and is distributed from southeastern Mexico to southern Brazil (4). Some species of this genus are known for their aromatic fragrances and their medicinal properties (5). Previous phytochemical and pharmacological investigations on some Guatteria species revealed cytotoxic effects, antimicrobial properties and antiparasitic activity (6-9). These bioactivities are attributed to the presence of terpenes and alkaloids in these plant species.
Guatteria friesiana (W.A. Rodrigues) Erkens \& Maas (synonym Guatteriopsis friesiana W.A. Rodrigues) is a small tree known as both 'envireira' and 'envira' found in the Brazilian and Colombian Amazon Basin (10). Previous phytochemical investigations on this species described the chemical constituents of its essential oils (11-13), as well as the presence of alkaloids $(10,14)$. The essential oils and alkaloids exhibited antitumor, antimicrobial properties (10, 11, 14), and larvicidal activity against Aedes aegypti larvae (12).

Guatteria pogonopus Martius is a tree characterized by very large leaves and short pedicel of flowers and fruits. It was reported to grow in the Brazilian states of Bahia, Espírito Santo, Minas Gerais, and Sergipe (15). Previous phytochemical studies on these species described the isolation of alkaloids, as well as, yours cytotoxic activities and the composition of the essential oil $(15,16)$.

In the continuous search for antiparasitic compounds from Brazilian Annonaceous plants, herein, the chemical composition and antiparasitic activity of the essential oils 
from the leaves of $G$. friesiana and G. pogonopus were investigated.

\section{Experimental}

\section{Plant material}

Leaves of G. friesiana were collected at the Experimental Farm of the Federal University of Amazonas (UFAM), Manaus, Amazonas, Brazil. The plant sample was identified Annonaceae by specialist Dr. Antonio Carlos Webber from the Federal University of Amazonas. A voucher specimen (No. 9282) was deposited in the Herbarium of the Department of Biology, UFAM. The G. pogonopus leaves were collected in the Itabaiana Mountain National Park, Itabaiana, Sergipe, Brazil. The plant material was identified by Dr. Ana Paula do Nascimento Prata, a plant taxonomist from the Department of Biology, Federal University of Sergipe, Brazil, and a voucher specimen (No. 22793) has been deposited with the Herbarium of the Federal University of Sergipe. Leaves were obtained, in March 2013, from flowered plants.

\section{Hydrodistillation of the essential oil}

The essential oils from dried leaves (for 72 hours) of the two Guatteria species (200 g each) were obtained by hydrodistillation for 3 hours using a Clevenger-type apparatus. The essential oils were dried over anhydrous sodium sulphate and the percentage content was calculated on the basis of the dry weight of plant material [Essential oil\% $=($ volume of the essential oil obtained $\times$ density/dried mass of leaves) $\times 100 \%]$. The extraction was performed in triplicate. The essential oils were stored in a freezer until analysis.

\section{GC-FID and CG-MS analysis of the essential oil}

GC-FID and GC-MS analyses were performed on a Shimadzu GC-2010 Plus GCMS-QP2010 Ultra GC-FID, equipped with a Shimadzu AOC-20i auto-injector. The separation of the compounds was achieved on a $\mathrm{RTx}^{\circ}$ $5 \mathrm{MS}$ fused capillary chromatography column $(30 \mathrm{~m} \times$ $0.25 \mathrm{~mm} \times 0.25 \mu \mathrm{m}$ film thickness) coated with $5 \%$-diphenyl-95\%-dimethylpolysiloxane. Helium was the carrier gas at $1.2 / \mathrm{min}$ flow rate. The column temperature program was $40^{\circ} \mathrm{C}$ for $4 \mathrm{~min}$, at a rate of $4^{\circ} \mathrm{C} / \mathrm{min}$ to $240^{\circ} \mathrm{C}$, then at $10^{\circ} \mathrm{C} / \mathrm{min}$ to $280^{\circ} \mathrm{C}$, and at $280^{\circ} \mathrm{C} / 2 \mathrm{~min}$. The injector and detector temperatures were $250^{\circ} \mathrm{C}$ and $280^{\circ} \mathrm{C}$, respectively. Samples $\left(10 \mathrm{mg} / \mathrm{mL}\right.$ in $\left.\mathrm{CH}_{2} \mathrm{Cl}_{2}\right)$ were injected with a 1:30 split ratio. Retention indices were generated with a standard solution of $n$-alkanes $\left(\mathrm{C}_{8}-\mathrm{C}_{18}\right)$. Peak areas and retention times were measured by an electronic integrator. The relative amounts of individual compounds were computed from GC peak areas without a FID response factor correction. MS were taken at $70 \mathrm{eV}$ with scan intervals of $0.5 \mathrm{~s}$ and fragments from $40 \mathrm{Da}-550 \mathrm{Da}$. Essential oil components were identified by comparison of their retention times $\left(t_{R}\right)$ with those of standards and isolated compounds under identical conditions as well as by their retention indices of a series of $n$-alkanes (17), and their mass spectra with those in the NIST $(05,05 \mathrm{~s}, 21$ and 107) and Wiley 8 mass spectral libraries, and published data in the literature (18). The analyses of the essential oil were performed in triplicate.

\section{Animals and parasites}

$\mathrm{BALB} / \mathrm{c}$ female mice (8 to 10 weeks old) were maintained in sterilized cages under a controlled environment, receiving a balanced rodent diet and water ad libitum at Centro de Pesquisas Gonçalo Moniz (Fundação Oswaldo Cruz, Bahia, Brazil). All animal experiments and procedures were carried out in accordance with the recommendations of the institution's committee on the ethical handling of laboratory animals. Epimastigotes of Trypanosoma cruzi (Y strain) were maintained in axenic medium at $26^{\circ} \mathrm{C}$, with weekly transfers into LIT medium(Liver Infusion Tryptose) supplemented with $10 \%$ fetal bovine serum (FBS; Cultilab, Campinas, SP, Brazil), 1\% hemin (Sigma, Chemical Co., St. Luis, MO), 1\% R9 medium (Sigma), and $50 \mu \mathrm{g} / \mathrm{mL}$ of gentamycin (Novafarma, Anápolis, GO, Brazil) (19). Tissue culture trypomastigotes (Y strain) were obtained from the supernatants of infected LLC-MK2 cells maintained in RPMI-1640 medium supplemented with $10 \% \mathrm{FBS}$ and $50 \mu \mathrm{g} / \mathrm{mL}$ of gentamycin at $37^{\circ} \mathrm{C}$ in a $5 \%$ humidified $\mathrm{CO}_{2}$ atmosphere (20). W2 strain Plasmodium falciparum (chloroquine-resistant) was maintained in continuous culture of human erythrocytes (blood group $\mathrm{O}^{+}$) using the RPMI 1640 medium supplemented with $10 \%$ of human plasma (21).

\section{Cytotoxicity to mammalian cells}

Peritoneal exudate macrophages were obtained by washing, with cold RPMI medium, the peritoneal cavity of $\mathrm{BALB} / \mathrm{c}$ mice 4-5 days after injection of $3 \%$ thioglycolate in saline (1.5 mL per mice). Then, cells were seeded on 96-well plates at a cell density $1 \times 10^{5}$ cells/well in RPMI1640 medium supplemented with $10 \%$ of FBS and $50 \mu \mathrm{g} /$ $\mathrm{mL}$ of gentamycin and incubated for 24 hours at $37^{\circ} \mathrm{C}$ and $5 \% \mathrm{CO}_{2}$. Then, each essential oil was added at five concentrations ranging from $1.23 \mu \mathrm{g} / \mathrm{mL}$ to $100 \mu \mathrm{g} / \mathrm{mL}$ in triplicate before being incubated for 72 hours. The cytotoxic effect was measured by the Alamarblue assay as described by Meira et al. (22). Gentian violet was used as positive control, at concentrations ranging from 0.04 to $10 \mu \mathrm{g} / \mathrm{mL}$. 


\section{Antimalarial activity}

Parasites grown at 1-2\% parasitemia and 2.5\% hematocrit were plated onto 96-wells plate and incubated with the compounds at different concentrations ranging from $1.23 \mu \mathrm{g} / \mathrm{mL}$ to $100 \mu \mathrm{g} / \mathrm{mL}$ in culture medium (RPMI 1640). After 24 hours, $\left[{ }^{3} \mathrm{H}\right]$-hypoxanthine (Perkin Elmer, Waltham, MA) was added, the plate were incubated again and parasites were harvested using a cell harvester to quantify the $\left[{ }^{3} \mathrm{H}\right]$-hypoxanthine incorporation in a $\beta$ radiation counter. Inhibition of parasite growth was evaluated by comparison with $\left[{ }^{3} \mathrm{H}\right]$-hypoxanthine uptake in treated cultures versus untreated culture (23). Mefloquine (Farmaguinhos, Rio de Janeiro, RJ, Brazil) was used as standard drug.

\section{Trypanocidal activity}

Epimastigotes $\left(1 \times 10^{6}\right.$ cells/well $)$ were placed in LIT medium in the absence or presence of the essential oils at five concentrations (100 to $1.23 \mu \mathrm{g} / \mathrm{mL}$ ). The effect of the treatment on epimastigotes proliferation was observed 5 days after incubation by counting viable forms in a Neubauer chamber. Bloodstream trypomastigotes forms of T. cruzi were cultured in 96 -well plates $\left(4 \times 10^{5}\right.$ cell/well $)$ in RPMI medium supplemented with $10 \%$ FBS and 50 $\mu \mathrm{g} / \mathrm{mL}$ of gentamycin in the absence or presence of different concentrations of the essential oils, in triplicate. After 24 hours of incubation, the number of viable parasites was assessed in a Neubauer chamber (24). The percentage of inhibition was calculated in relation to untreated cultures. Benznidazole (LAFEPE, Recife, PE, Brazil) was used as positive control.

\section{In vitro macrophage infection and treatment with essential oils}

Peritoneal macrophages $\left(2 \times 10^{5}\right.$ cells/well $)$ obtained from $\mathrm{BALB} / \mathrm{c}$ mice were seeded in a twenty-four well-plate with rounded coverslips on the bottom in RPMI supplemented with $10 \%$ FBS and incubated for 24 hours. Cells were then infected with trypomastigotes (1:10) for 2 hours. Free trypomastigotes were removed by successive washes using saline solution. Cultures were incubated for 24 hours to allow full internalization and differentiation of trypomastigotes to amastigotes. Next, cultures were incubated in complete medium alone or with the essential oil EOGF ( 5 or $10 \mu \mathrm{g} / \mathrm{mL}$ ) for 72 hours. Cells were fixed in absolute alcohol and the percentage of infected macrophages and the relative number of amastigotes per 100 macrophages was determined by manual counting after hematoxylin and eosin staining in an optical microscope (Olympus, Tokyo, Japan). The percentage of infected macrophages and the number of amastigotes per 100 macrophages was determined by counting 100 cells per slide. Benznidazole $(10 \mu \mathrm{g} / \mathrm{mL})$ was used as the positive control.

\section{Electron microscopy analysis}

Trypomastigotes $\left(3 \times 10^{7}\right.$ cells/well $)$ were incubated for 24 hours at $37^{\circ} \mathrm{C}$ in complete medium alone or with the essential oil EOGF $(10.7 \mu \mathrm{g} / \mathrm{mL}$ or $21.4 \mu \mathrm{g} / \mathrm{mL})$. After incubation, parasites were fixed for 1 hour at room temperature with $2 \%$ formaldehyde and $2.5 \%$ glutaraldehyde (Electron Microscopy Sciences, Hatfield, PA) in sodium cacodylate buffer $(0.1 \mathrm{M}, \mathrm{pH} 7.2)$ for 1 hour at room temperature. After fixation, parasites were processed for transmission electron microscopy (TEM) as previously described (22). Images were captured in a JEOL TEM1230 transmission electron microscope.

\section{Statistical analyses}

To determine the cytotoxicity concentration $50 \%\left(\mathrm{CC}_{50}\right)$ and inhibitory concentration $50 \%\left(\mathrm{IC}_{50}\right)$ for epimastigote and trypomastigote forms of T. cruzi, we used nonlinear regression on Prism 5.02 GraphPad software (Graph Pad Software, San Diego, CA). The one-way ANOVA and Bonferroni for multiple comparisons were used to determine the statistical significance of the group comparisons. Differences were considered significant when the values of $P$ were $<0.05$. All experiments were done at least twice.

\section{Results and discussion}

Hydrodistillation of the leaves of G. friesiana (EOGF) and G. pogonopus (EOGP) gave a solid white and red color rude essential oils, with a yield of $1.17 \pm 0.14 \%$ and 0.22 $\pm 0.03 \%$ (w/w, based on the dry weight of the plant material), respectively. The sesquiterpenes compounds were the most abundant in the essential oils investigated, comprising $93.0 \%$ in EOGF and $88.4 \%$ in EOGP, compared to the total chemical composition of each essential oil identified (Table 1). Moreover, it was possible to identify twenty-four compounds; eight in EOGF, and nineteen in EOGP (Table 1).

These results of the GC-FID and GC-MS analyses confirm the results reported by Costa et al. (11) that $G$. friesiana are dominated by $\beta$-eudesmol (51.9\%), $\gamma$-eudesmol (18.9\%), $\alpha$-eudesmol (12.6\%), and elemol (4.3\%). The major compounds identified for essential oil of G. pogonopus were spathulenol (24.8\%), $\gamma$-amorphene (14.7\%), germacrene D (11.7\%), (E)-caryophyllene (4.8\%), $\gamma$-elemene (4.2\%), caryophyllene oxide (4.0\%), (Z)-caryophyllene (3.9\%), alloaromadendrene epoxide (3.6\%), $\gamma$-muurolene (3.5\%), and germacrene B (3.0\%). These results differ 
Table 1. Essential oil composition of Guatteria species.

\begin{tabular}{|c|c|c|c|c|}
\hline \multirow[b]{2}{*}{ Compounds } & \multirow[b]{2}{*}{$\mathrm{RI}^{\mathrm{a}}$} & \multirow[b]{2}{*}{$\mathrm{Rl}^{\mathrm{b}}$} & \multicolumn{2}{|c|}{ Leaf oil \% } \\
\hline & & & G. friesiana & G.pogonopus \\
\hline a-Ylangene & 1369 & 1373 & - & $1.05 \pm 0.58$ \\
\hline a-Copaene & 1379 & 1374 & - & $1.19 \pm 0.34$ \\
\hline$\beta$-Elemene & 1393 & 1389 & - & $1.04 \pm 0.19$ \\
\hline (Z)-Caryophyllene & 1407 & 1408 & - & $3.87 \pm 0.08$ \\
\hline (E)-Caryophyllene & 1422 & 1417 & - & $4.82 \pm 0.30$ \\
\hline$\gamma$-Elemene & 1430 & 1434 & - & $4.24 \pm 0.20$ \\
\hline cis-Muurola-3,5-diene & 1447 & 1448 & - & $1.78 \pm 0.25$ \\
\hline Spirolepechinene & 1453 & 1449 & - & $2.66 \pm 0.20$ \\
\hline$\gamma$-Muurolene & 1473 & 1478 & - & $3.53 \pm 1.60$ \\
\hline Germacrene D & 1484 & 1484 & - & $11.75 \pm 6.33$ \\
\hline$\gamma$-Amorphene & 1494 & 1495 & - & $14.72 \pm 3.37$ \\
\hline Bicyclogermacrene & 1500 & 1500 & - & $0.24 \pm 0.05$ \\
\hline$\gamma$-Patchoulene & 1506 & 1502 & - & $0.51 \pm 0.07$ \\
\hline$\delta$-Cadinene & 1517 & 1522 & - & $0.15 \pm 0.02$ \\
\hline Elemol & 1548 & 1548 & $4.31 \pm 1.33$ & - \\
\hline Germacrene B & 1563 & 1559 & - & $3.01 \pm 0.61$ \\
\hline Spathulenol & 1576 & 1577 & $2.76 \pm 0.78$ & $24.80 \pm 11.38$ \\
\hline Caryophyllene oxide & 1580 & 1582 & $0.41 \pm 0.24$ & $3.97 \pm 2.08$ \\
\hline Globulol & 1596 & 1590 & - & $1.43 \pm 0.49$ \\
\hline 10-Epi-Y-eudesmol & 1620 & 1622 & $0.99 \pm 0.40$ & - \\
\hline$\gamma$-Eudesmol & 1633 & 1630 & $18.91 \pm 5.41$ & - \\
\hline Alloaromadendrene Epoxide & 1639 & 1639 & $1.13 \pm 0.27$ & $3.62 \pm 1.03$ \\
\hline$\beta$-Eudesmol & 1648 & 1649 & $51.92 \pm 9.15$ & - \\
\hline$a$-Eudesmol & 1651 & 1652 & $12.56 \pm 2.80$ & - \\
\hline Sesquiterpenes identified & & & $93.0 \pm 1.7$ & $88.4 \pm 2.8$ \\
\hline Total identified & & & $93.0 \pm 1.7$ & $88.4 \pm 2.8$ \\
\hline
\end{tabular}

Note: Data are expressed as mean \pm SD of three analyses. RI (retention indices): acalculated on RTx ${ }^{\oplus}-5 \mathrm{MS}$ column according to VanDen Dool and Kratz (17), based on a homologous series of normal alkanes; baccording to Adams (18).

Table 2. Cytotoxicity against macrophages, effect on erythrocitic stages of Plasmodium falciparum and trypanocidal action against bloodstream trypomastigotes and epimastigotes forms of T. cruzi (Y strain) of the essential oils of G. friesiana (EOGF) and G. pogonopus (EOGP).

\begin{tabular}{lcccc}
\hline Sample & $\mathrm{CC}_{50}(\mu \mathrm{g} / \mathrm{mL})$ & $\mathrm{IC}_{50}(\mu \mathrm{g} / \mathrm{mL})$ Pal. & $\mathrm{IC}_{50}(\mu \mathrm{g} / \mathrm{mL}) \operatorname{Try}$. & $\mathrm{IC}(\mu \mathrm{g} / \mathrm{mL}) \mathrm{Epi}$. \\
\hline EOGF & $37.7( \pm 3.6)$ & $0.53( \pm 0.1)$ & $10.7( \pm 1.3)$ & $11.9( \pm 1.2)$ \\
EOGP & $>100$ & $6.8( \pm 1.7)$ & $41.3( \pm 0.6)$ & $28.0( \pm 0.6)$ \\
Benznidazole $^{\mathrm{a}}$ & - & - & $2.7( \pm 0.5)$ & $2.7( \pm 0.7)$ \\
Mefloquine $^{\mathrm{b}}$ & - & $0.02( \pm 0.0)$ & - & - \\
Gentian violet $^{c}$ & $0.19( \pm 0.0)$ & - & - & - \\
\hline
\end{tabular}

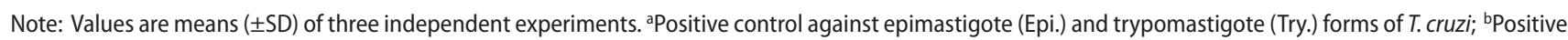
control against $P$. falciparum (Pla.); cPositive control against mammalian cells.

somewhat from study by Fontes et al. (15), especially for the absence of monoterpene compounds. These variations or detector sensitivity or sample dilution in the composition of the major constituents of G. pogonopus, as well as the contents of all components, can be related to soil and climate conditions, water stress, collection place, nutrition and other biotic factors (24).

After elucidated the chemical composition of the essential oils EOGF and EOGP their antiparasitic activity against $P$. falciparum and different forms of T. cruzi was investigated. The essential oils displayed potent antimalarial activity against erythrocitic stages of $P$. falciparum and trypanocidal action against bloodstream trypomastigotes and epimastigotes forms of T. cruzi. As revealed in Table 2, EOGF and EOGP presented an $\mathrm{IC}_{50}$ of $0.5 \mu \mathrm{g} / \mathrm{mL}$ and 6.8 $\mu \mathrm{g} / \mathrm{mL}$, respectively against $P$. falciparum, an $\mathrm{IC}_{50}$ of 11.9 $\mu \mathrm{g} / \mathrm{mL}$ and $28 \mu \mathrm{g} / \mathrm{mL}$ respectively against epimastigotes forms of T. cruzi and an $\mathrm{IC}_{50}$ of $10.7 \mu \mathrm{g} / \mathrm{mL}$ and $41.3 \mu \mathrm{g} /$ $\mathrm{mL}$, respectively against trypomastigotes forms of T. cruzi. The cytotoxicity of essential oils against mammalian cells was also determined. EOGF showed a $\mathrm{CC}_{50}$ value of 37.7 $\mu \mathrm{g} / \mathrm{mL}$ and EOGP showed no toxicity in this assay, having a $\mathrm{CC}_{50}$ higher than $100 \mu \mathrm{g} / \mathrm{mL}$ (Table 2), therefore being selective antiparasitic compounds.

To understand how the essential oils affect intracellular forms of T. cruzi, an in vitro model of mouse macrophages infected with $\mathrm{Y}$ strain was performed. As revealed in Figure 1, both concentrations of EOGF significantly reduced the number of infected macrophages $(P<0.05)$ and the higher concentration was able to decrease the 
(A)

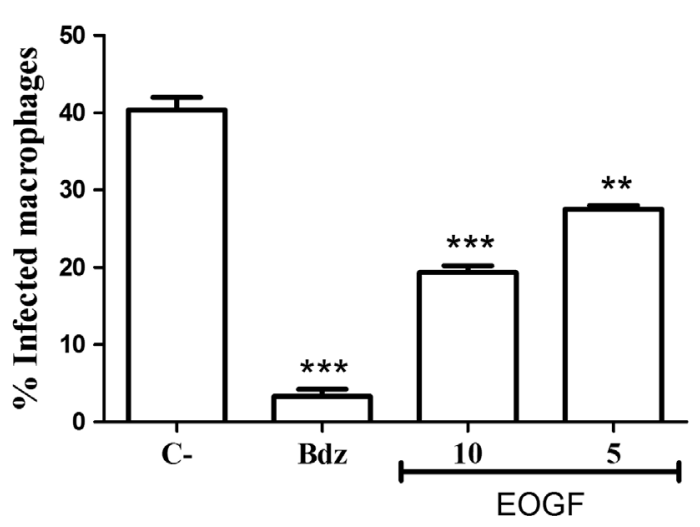

(B)

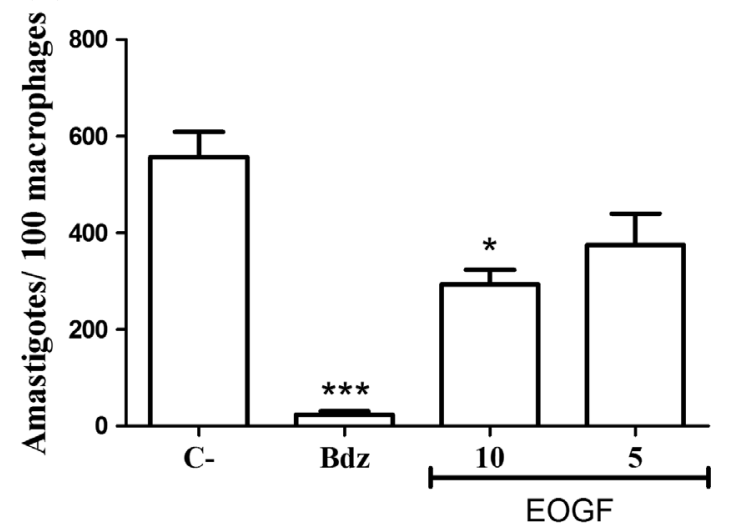

Figure 1. Effect of essential oil from Guatteria friesiana on T. cruzi amastigotes proliferation in macrophages. Mouse peritoneal macrophages were infected with T. cruzi and treated with the essential oil EOGF (5 or $10 \mu \mathrm{g} / \mathrm{mL})$ or benznidazole $(5 \mu \mathrm{g} / \mathrm{mL})$, a standard drug, for 72 hours. Number of infected cells (A) and amastigotes (B) were determined by couting hematoxylin and eosin-stained cultures. $\mathrm{C}$ - is negative control. Bdz is benznidazole. Values represent the mean \pm SEM of triplicates. ${ }^{*} P<0.05 ;{ }^{* *} P<0.01 ;{ }^{* * *} P<0.001$ compared to infected and untreated cultures.
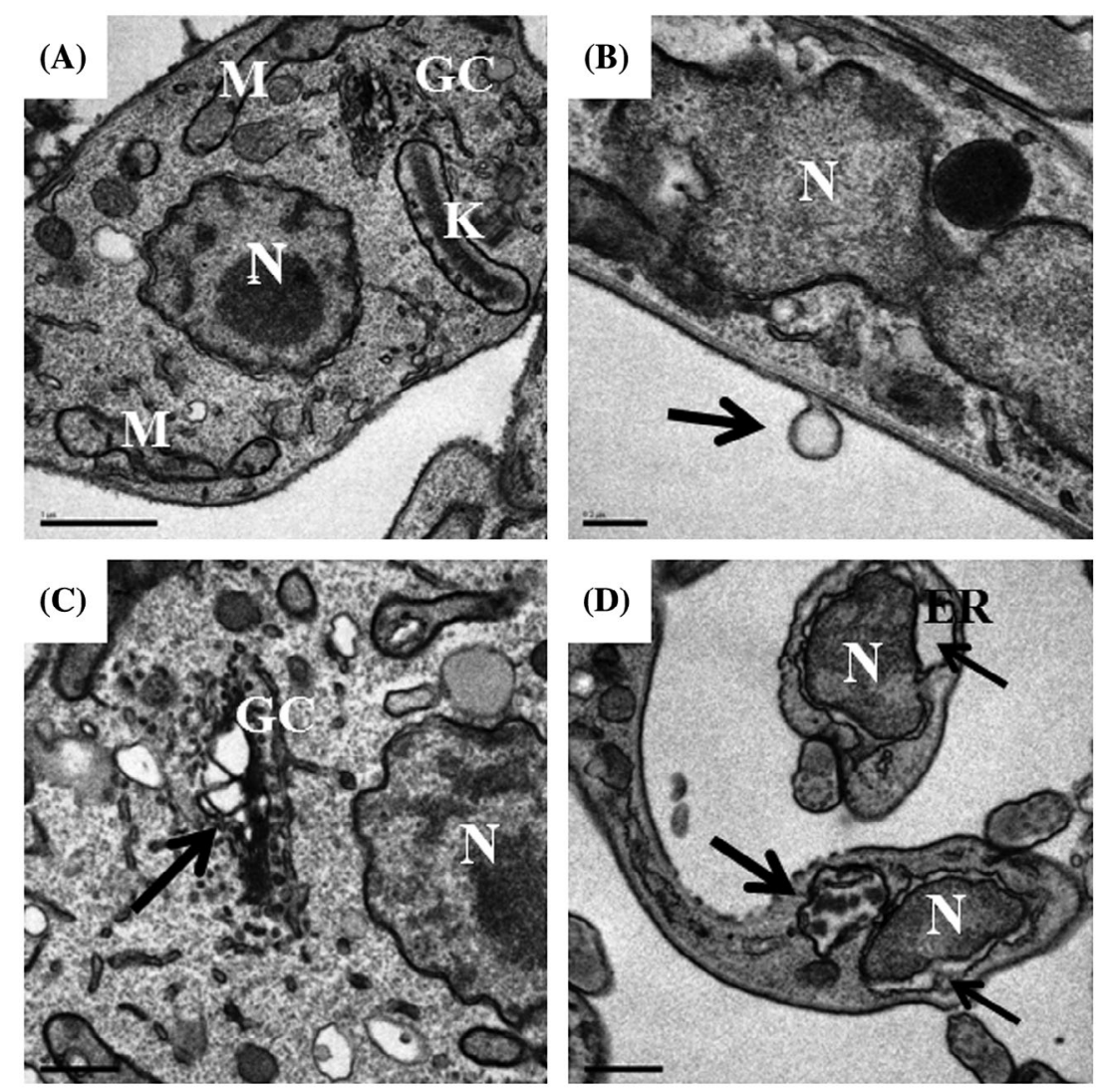

Figure 2. Transmission electron micrographs of trypomastigotes treated or not with EOGF for 24 hours. (A) shows an image of untreated trypomastigotes presenting a typical morphology of the nucleus (N), kinetoplast (K), mitochondria (M) and Golgi complex (GC). Treatment with EOGF at $10.7 \mu \mathrm{g} / \mathrm{mL}$ (B-C) and $21.4 \mu \mathrm{g} / \mathrm{mL}$ (D) causes alterations in parasite plasma membrane (B), Golgi complex disorganization (C), mitochondrial disruption and alteration in ER membrane (D). Black arrows indicate changes in organelles. Scale bars: $A=1 \mu \mathrm{m} ; \mathrm{B}$ and $\mathrm{D}=0.5 \mu \mathrm{M} ; \mathrm{C}=0.2 \mu \mathrm{m}$.

number of amastigotes. Benznidazole, under the same conditions, was more effective than the essential oil.

Finally, after confirming that essential oils were able to kill parasitic cells, we performed electron microscopy analysis to understand how they affect parasite cells. For this purpose we used transmission electron microscopy (TEM) to examine the ultrastructural morphology of trypomastigotes (Y strain) treated with EOGF (10.7 or $21.4 \mu \mathrm{g} / \mathrm{mL}$ ) 
for 24 hours. As we can see in Figure 2, thin sections of untreated trypomastigotes observed by TEM revealed normal appearance of organelles, intact plasma membrane and parasite cytoplasm without alterations (Figure $2 \mathrm{~A})$. However, the treatment with EOGF $(10.7 \mu \mathrm{g} / \mathrm{mL})$ caused plasma membrane alterations (Figure 2B) and disorganization of Golgi complex (Figure 2C). Degeneration of mitochondria and alteration in membranes of endoplasmic reticulum were also observed on parasites treated with $21.4 \mu \mathrm{g} / \mathrm{mL}$ of EOGF (Figure 2D). Structural alterations in Golgi complex and endoplasmic reticulum are common on parasites treated with cruzain inhibitors, the major cysteine protease of parasite (25). On the other hand, alterations on plasma membrane and on mitochondrial morphology indicate depletion on parasite metabolism (26). Thus, further investigations are necessary to clarify how the essential oils from Guatteria species promote parasite cell death.

In conclusion, the low cytotoxicity and the higher antiparasitic activity of essential oils from Guatteria species reinforce the potential of Annonaceae species for development of safer antiparasitic drugs.

\section{Acknowledgments}

The authors are grateful to CNPq, CAPES, FAPITEC/SE, and FAPESB for financial support.

\section{Disclosure statement}

No potential conflict of interest was reported by the authors.

\section{Funding}

This work was supported by the Conselho Nacional de Desenvolvimento Científico e Tecnológico [grant number 301837/2015-5]; Fundação de Amparo à Pesquisa do Estado da Bahia [grant number PET0042/2013]; Programa de Apoio a Núcleos de Excelência [grant number PNX0002/2014].

\section{References}

1. F. Scala, E. Fattorusso, M. Menna, O. Taglialatela-Scafati, M. Tierney, M. Kaiser and D. Tasdemir, Bromopyrrole alkanoids as lead compounds against protozoan parasites. Marine Drugs, 8, 2162-2174 (2010).

2. F. Sánchez-Sancho, N.E. Campillo and J.A. Páez, Chagas disease: progress and new perspectives. Curr. Med. Chem., 17, 423-452 (2010).

3. C.J.L. Murray, L.C. Rosenfeld, S.S. Lim, K.G. Andrews, K.J. Foreman, D. Haring, N. Fullman, M. Naghavi, R. Lozano and A.D. Lopez, Global malaria mortality between 1980 and 2010: a systematic analysis. Lancet, 379, 413-431 (2012).

4. R.H.J. Erkens, L.Y.T. Westra and P.J.M. Maas, Increasing diversity in the species-rich genus Guatteria (Annonaceae). Blumea, 53, 467-514 (2008).
5. M.P. Corrêa, Dicionário das plantas úteis do Brasil e das exóticas cultivadas., IBDF, Rio de Janeiro, RJ (1984).

6. V. Mahiou, F. Roblot, A. Fournet and R. Hocquemiller, Bisbenzylisoquinoline alkaloids from Guatteria boliviana (Annonaceae). Phytochemistry, 54, 709-716 (2000).

7. E.V. Costa, M.L.B. Pinheiro, A. Barison, F.R. Campos, M.J. Salvador, B.H.L.N.S. Maia, E.C. Cabral and M.N. Eberlin, Alkaloids from the bark of Guatteria hispida and their evaluation as antioxidant and antimicrobial agents. J. Nat. Prod., 73, 1180-1183 (2010).

8. E.V. Costa, F.A. Marques, M.L.B. Pinheiro, R.M. Braga, C. Delarmelina, M.C.T. Duarte, A.L.T.G. Ruiz, J.E. Carvalho and B.H.L.N.S. Maia, Chemical constituents isolated from the bark of Guatteria blepharophylla (Annonaceae) and their antiproliferative and antimicrobial activities. J. Braz. Chem. Soc., 22, 1111-1117 (2011).

9. S.S. Ribeiro, A.M. Jesus, C.S. Anjos, T.B. Silva, A.D. Santos, J.R. Jesus, M.S. Andrade, T.S. Sampaio, W.F. Gomes, P.B. Alves, A.A. Carvalho, C. Pessoa, M.O. Moraes, M.L.B. Pinheiro, A.P. Prata, A.F. Blank, R. Silva-Mann, V.R. Moraes, E.V. Costa, P.C. Nogueira and D.P. Bezerra, Evaluation of the cytotoxic activity of some Brazilian medicinal plants. Planta Medica, 78, 1601-1606 (2012).

10. E.V. Costa, P.E.O. Cruz, M.L.B. Pinheiro, F.A. Marques, A.L.T.G. Ruiz, G.M. Marchetti, J.E. Carvalho, A. Barison and B.H.L.N.S. Maia, Aporphine and tetrahydroprotoberberine alkaloids from the leaves of Guatteria friesiana (Annonaceae) and their cytotoxic activities. J. Braz. Chem. Soc., 24, 788-796 (2013).

11. E.V. Costa, S.D. Teixeira, F.A. Marques, M.C.T. Duarte, C. Delarmelina, M.L.B. Pinheiro, J.R. Trigo and B.H.L.N.S. Maia, Chemical composition and antimicrobial activity of the essential oils of the Amazon Guatteriopsis species. Phytochemistry, 69, 1895-1899 (2008).

12. S.D.G. Aciole, C.F. Piccoli, L.J.E. Duque, E.V. Costa, M.A. Navarro-Silva, F.A. Marques, B.H.L.N.S. Maia, M.L.B. Pinheiro and M.T. Rebelo, Insecticidal activity of three species of Guatteria (Annonaceae) against Aedes aegypti (Diptera: Culicidae). Revista Colombiana de Entomologia, 37, 262-268 (2011).

13. A.C.S. Britto, A.C. Oliveira, R.M. Henriques, G.M.B. Cardoso, D.S. Bomfim, A.A. Carvalho, M.O. Moraes, C. Pessoa, M.L.B. Pinheiro, E.V. Costa and D.P. Bezerra, In vitro and in vivo antitumor effects of the essential oil from the leaves of Guatteria friesiana. Planta Medica, 78, 409-414 (2012).

14. E.V. Costa, F.A. Marques, M.L.B. Pinheiro, N.P. Vaz, M.C.T. Duarte, C. Delarmelina, R.M. Braga and B.H.L.N.S. Maia, 7,7-Dimethylaporphine alkaloids from the stem of Guatteriopsis friesiana. J. Nat. Prod., 72, 1516-1519 (2009).

15. J.E. Fontes, P.C. Ferraz, A.C.S. Britto, A.A. Carvalho, M.O. Moraes, C. Pessoa and E.V. Costa, Antitumor effect of the essential oil from leaves of Guatteria pogonopus (Annonaceae). Chem. Biodiv., 10, 722-729 (2013).

16. M.F.C. Santos, L.M. Dutra, V.R.S. Moraes, A. Barison and E.V. Costa, Aporphine alkaloids from the stem bark of Guatteria pogonopus (Annonaceae). Biochem. Syst. Ecol., 60, 106-109 (2015).

17. H. Van Den Dool and P.D. Kratz, A generalization of the retention index system including linear temperature programmed gas-liquid partition chromatography. J. Chromatogr., 11, 463-471 (1963). 
18. R.P. Adams, Identification of Essential Oil Components by Gas Chromatography/Mass Spectrometry., Allured Publ. Corp, Carol Stream, IL (2007).

19. E.P. Camargo, Growth and differentiation in Trypanosoma cruzi. Origin of metacyclic trypanosomes in liquid media. Revista do Instituto de Medicina Tropical de São Paulo, 6, 93-100 (1964).

20. M.N. Meirelles, T.C. Araújo Jorge and W. Souza, Interaction of Trypanosoma cruzi with macrophages in vitro: dissociation of the attachment and internalization pahses by low temperature and cytochalasin B. Zeitschrift für Parasitenkunde, 68, 6-14 (1982).

21. W. Trager and J.B. Jensen, Human malaria parasites in continuous culture. 1976. J. Parasitol., 91, 484-486 (2005).

22. C.S. Meira, E.T. Guimarães, T.M. Bastos, D.R. Moreira, T.C. Tomassini, I.M. Ribeiro, R.R. Santos and M.B.P. Soares, Physalins B and F, seco-steroids isolated from Physalis angulata L., strongly inhibit proliferation, ultrastructure and infectivity of Trypanosoma cruzi. Parasitology, 140, 1811-1821 (2013).

23. R. Desjardins, C. Canfield, J. Haynes and J. Chulay, Quantitative assessment of antimalarial activity in vitro by a semiautomated microdiluition technique. Antimicro. Agent Chemother., 16, 710-718 (1979).

24. T.B. Silva, L.R.A. Menezes, M.F.C. Sampaio, C.S. Meira, E.T. Guimarães, M.B.P. Soares, A.P.N. Prata, P.C.L. Nogueira and E.V. Costa, Chemical composition and antiTrypanosoma cruzi activity of essential oils obtained from leaves of Xylopia frutescens and X. laevigata (Annonaceae). Nat. Prod. Comm., 8, 403-406 (2013).

25. J.C. Engel, P.S. Doyle, J. Palmer, I. Hsieh, D.F. Bainton and J.H. Mckerrow, Cysteine protease inhibitors alter Golgi complex ultrastructure and function in Trypanosoma cruzi. J. Cell Sci., 111, 597,606 (1998).

26. M.A. Vannier-Santos and S.L. De Castro, Electron microscopy in antiparasitic chemotherapy: a (Close) view to a kill. Curr. Drug Targ., 10, 246-260. 